\title{
QR CODE AND VIDEO MONITORING BASED DOOR OPENING SYSTEM USING ANDROID APPLICATION
}

\author{
K.Ananda ${ }^{1}$, Priya Pandey ${ }^{2}$, Shagun Srivastava ${ }^{3}$ \\ ${ }^{1}$ Assistant Professor, Dept. of ISE, Sri Krishna Inst. of Tech., Bengaluru, India, \\ ${ }^{2}$ Student of Bachelor of Engineering, Dept. of ISE, Sri Krishna Inst. of Tech., Bengaluru, India, \\ ${ }^{3}$ Student of Bachelor of Engineering, Dept. of ISE, Sri Krishna Inst. of Tech., Bengaluru, India
}

\begin{abstract}
The main purpose of this paper is to unbind a hotel room door by an android application using a $Q R$ code. QR code i.e. Quick Response Code is the attribute for a type of two-dimensional barcode that is generated via an android application. A QR code uses four systematized encoding modes i.e. numbers, alphabets etc. to efficiently store data. It mainly contains of black squares that are arranged in a box shaped grid that is on a white background, which can be accessed by an imaging device such as a camera. An additional feature is also introduced in this paper i.e. video monitoring where a person is inside the room and someone knocks the door then with the help of video monitoring it can be unlocked for the right person.
\end{abstract}

Keywords - Android, Microcontroller, QR code, Smart phones, Video Monitoring,Wi-Fi.

$* * *$

\section{INTRODUCTION}

The framework is designed to provide safety in order to prevent the unwanted people coming inside the room. This system is designed as when a person checks in to a hotel, he needs to download the app of that hotel. When he downloads the app a unique QR code will be provided which will be a QR code of the room allotted to the user. The user will need to connect to the Wi-Fi provided by the hotel to use the QR code. Once the code is provided to the user he can unlock the door by scanning the QR code provided to him. If he goes to the correct door and scans the QR code the door opens and if it is the wrong door a siren starts ringing indicating that it is the wrong door. Now suppose someone is knocking the door and if the user doesn't want to actually go and open the door he can use the concept of video monitoring. This concept can help the person monitor the person standing outside the door by seeing the live video of that person in his android device. The person should be standing in the range specified by the sensor. If the person is within the range of the sensor, a notification will be sent to the user inside the room with the picture of the person standing outside the room to accept his entry. If the user accepts the request then the door will automatically open for the entry of the person. If the user doesn't accept the request the door doesn't open.

\section{QR CODE}

\subsection{Encryption of QR Code}

Encryption converts plain text to a human non-readable form that contains some kind of data or information which can be decrypted using some certain algorithm that uses a key. Encrypted QR codes cannot be read or accessed by everyone. It can be decrypted only using the key which was generated. Fig (a) shows the encryption of the QR code..

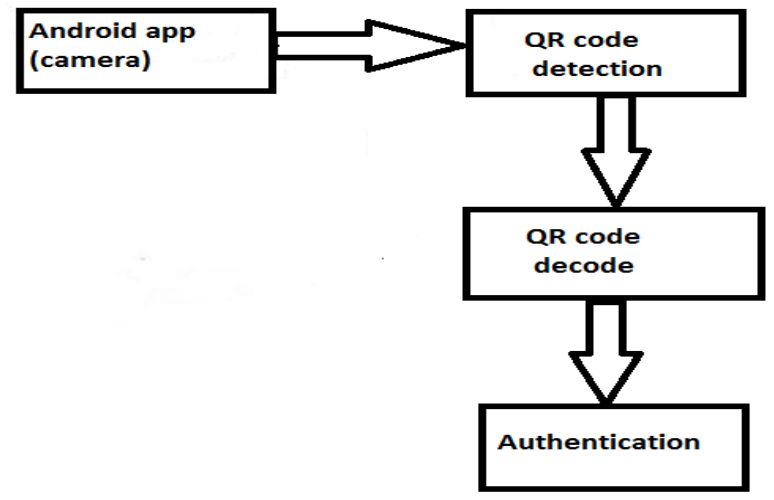

Fig (a): Encryption of the QR code.

\subsection{Design of QR Code}

Previously, one-dimensional barcodes were intended to examine by a constrict beam of light, a QR code is perceived by a 2-dimensional image sensor and then analyzed by a processor. The processor locates the three peculiar squares at the corners of the QR code image using a smaller square (or multiple squares) near the fourth corner to tabulate the image for size, orientation, and angle of viewing. The small dots all over the QR code are then converted to binary numbers and approved with an error-correcting code. Fig (b) shows how a QR Code looks. 


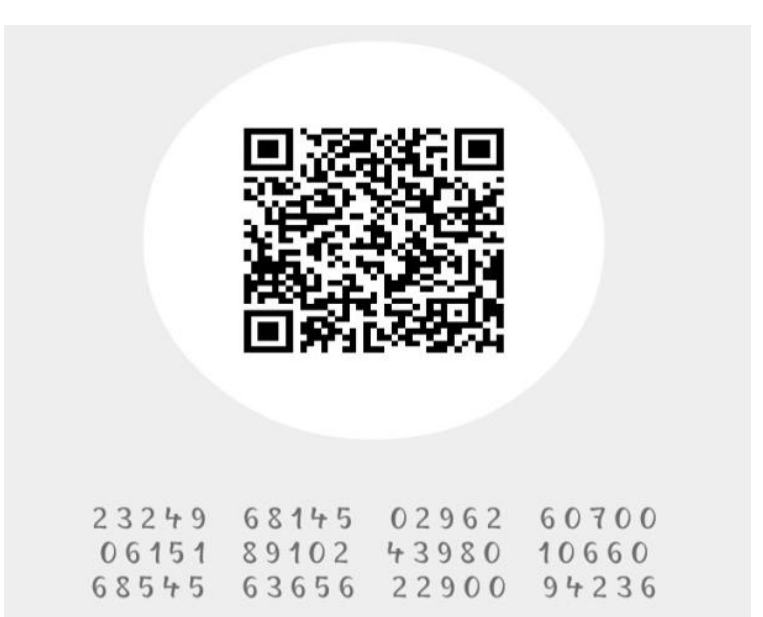

Fig (b): Example of a QR Code

\subsection{Video Monitoring}

Video monitoring is widely used nowadays for security reasons. It is used to capture the human motion, behavior and other activities in order to manage, protect people. This is basically done by using a camera attached at some distance which keeps the track of all the activities happening within the range of the camera. Here the camera is attached at some point around the door. When a person comes in the range of the camera and stands near the door and knocks the camera using the $\mathrm{WiFi}$ sends the photo of the person standing outside as the notification to the user inside the room. Once the user gets the notification he can accept or reject the request. If he accepts the door automatically opens for the person standing outside or doesn't open.

\section{SYSTEM ARCHITECTURE}

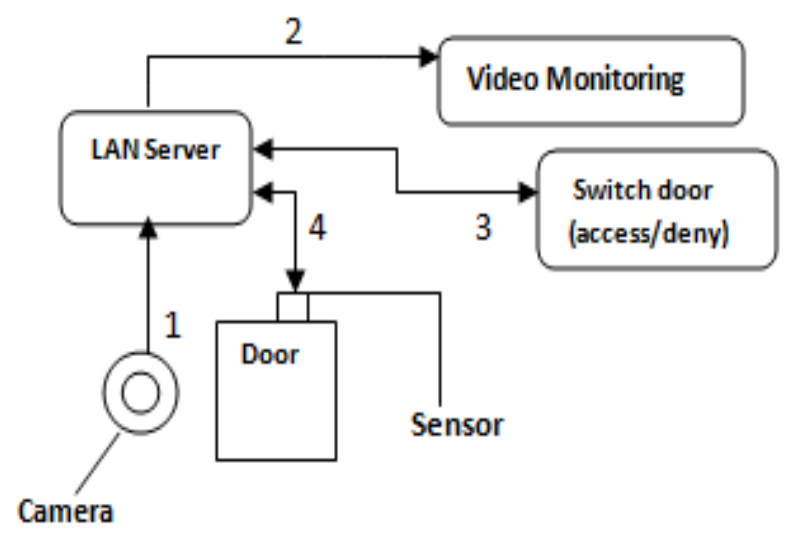

Fig 1: Video Monitoring diagram

Figure 1 shows the process of video monitoring. In the diagram the person outside the door can easily be captured through that network camera, once the image of the person is captured, the control will directly go to LAN server to which video monitoring is connected, where it monitors the person, and then the control will go to the network switch which will check whether the person standing outside the door is authenticated or not. If it is authenticated then the door gets opened or else it remains closed.

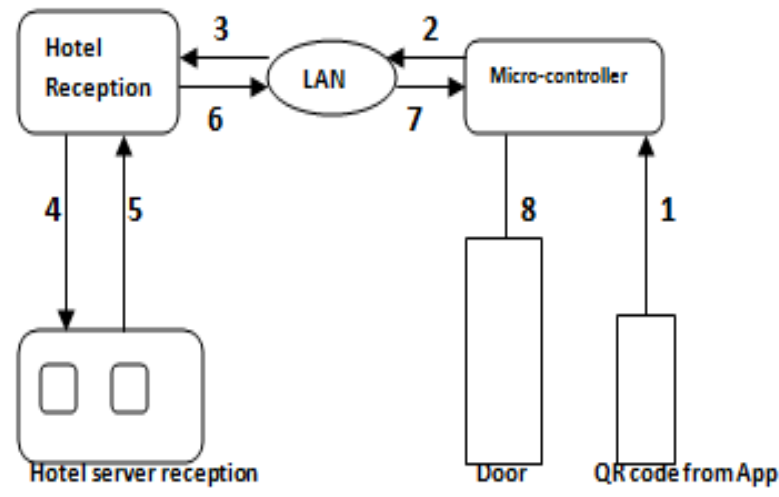

Fig 2: QR code diagram

Figure 2 illustrates the diagram of the QR code. The main task of this system is to open the hotel room after authentication of his/her booking owner against the room which he/she wants to open. Firstly the customer needs to download the respective hotel app to his/her android mobile, then through that app scan the QR code which is into that door. once it is scanned then control goes to microcontroller to which server accessing reception is connected where all the data of customer is stored, if it matches then the door gets open via sensor or else it remains closed/relay

\section{CONCLUSION}

Nowadays many people are in the developed countries. Hence everyone likes to work mostly on the smart phones and also they want their entire process to work of its own i.e. automatically. Because of this the use of online service and technology are increasing day by day. In our system the security is main factor because of $\mathrm{QR}$ code. The main purpose of this paper is to unlock the hotel room door by an android application via QR code. The unauthorized person cannot be easily enter inside the room because user and sensor is always encrypted.This paper also introduce the concept of video monitoring, where person is inside the room and someone knocks the door then with the help video monitoring concept it can unlocked for right person. This paper can be implemented further.

\section{REFERENCES}

[1]. David Pintor Maestre Universitat Oberta de Catalunya 08018, "QRP: An improved secure authentication method using QR codes”, Barcelona, June 8, 2012.

[2]. David Muñoz-Mejías, Ivan Gonzalez Diaz, Student Member, IEEE, and Fernando Diaz-de-Maria , Member, IEEE ,"A Low-Complexity Pre-Processing System for Restoring Low-Quality QR Code Images”, 2011.

[3]. Majdi Al- qdah \& Lin Yi Hui, Faculty of Information Technology Multimedia University Cyberjaya, 63100, Malaysia "Simple Encryption/Decryption Application".

[4]. Siquan $\mathrm{Hu}, \mathrm{Yu} \mathrm{Fu}$, School of Computer and Communication Engineering University of Science and Technology Beijing, Chundong She, Hui Yao, Ruijie Networks Co., Ltd, "Enabling Zigbee Communications in Android Devices", published in Proceedings of the 2012 2nd 
International Conference on Computer and Information Application (ICCIA 2012).

[5]. Kuan J.H. , Chang J. , Ho J. ," A development of information protection system using system engineering and RFID technolog", published in International Conference on System Science and Engineering (ICSSE), IEEE 2010.

[6]. Xi Li, Tiyan Shen, Jinjie Zhang, Changmin Shi, "A Spatial Technology Approach to Campus Security, Networking, Sensing and Control", 2008, published in ICNSC 2008.

[7]. Ushie James Ogri, Donatus Enang Bassey Okwong, Akaiso Etim, Department of Physics, University of Calabar, "DESIGN AND CONSTRUCTION OF DOOR LOCKING SECURITY SYSTEM USING GSM”, published in International Journal Of Engineering And Computer Science ISSN:2319-7242,Volume 2 Issue 7 (July 2013), Page No. 2235-2257. 